\title{
Oldest stone tools raise questions about their creators
}

The 3.3-million-year-old implements predate the first members of the Homo genus.

\section{BY EWEN CALLAWAY, SAN FRANCISCO}

$\mathrm{T}$ The oldest stone tools on record may spell the end for the theory that complex toolmaking began with the genus Homo, to which humans belong. The 3.3-million-year-old artefacts, revealed at a conference in California last week, predate the first members of Homo, and suggest that moreancient hominin ancestors had the intelligence and dexterity to craft sophisticated tools.

"This is a landmark discovery pertaining to one of the key evolutionary milestones," says Zeresenay Alemseged, a palaeoanthropologist at the California Academy of Sciences in San Francisco, who attended the talk at the annual meeting of the Paleoanthropology Society in San Francisco, on 14 April.

More than 80 years ago, anthropologist Louis Leakey found stone tools in Olduvai Gorge in Tanzania. Decades later, he and his wife Mary and their team found bones from a species that the Leakeys named Homo habilis - 'the handy man'. This led to the prevailing view that human stone-tool use began with Homo, a group that includes modern humans and their big-brained and tall forebears. The oldest of these Oldowan tools date to 2.6 million years ago - around the time of the earliest Homo fossils. Climate upheavals that transformed dense forest into open savannah might have catalysed ancient humans into developing the new technology so that they could hunt or scavenge grass-eating animals, the theory goes.

Chimpanzees and other non-human primates use stones to crack nuts, for instance, but their tools lack the craftsmanship of the Oldowan toolmakers, who would strike one rock against another, breaking off flakes to leave a sharp-edged stone core.

In 2010, Alemseged and his team reported an intriguing find at a site called Dikika in Ethiopia (S. P. McPherron et al. Nature 466, $857-860 ; 2010)$. They saw cut marks on bones from 3.4 million years ago, when ape-like creatures such as Australopithecus afarensis - the same species as the famous fossil called Lucy - roamed eastern Africa. This hinted at even earlier manufacturing of stone tools. Other researchers questioned the find, attributing the marks to natural wear and tear such as trampling, or bites inflicted by crocodiles.

Aware of this controversy, a team led by Sonia Harmand of Stony Brook University in

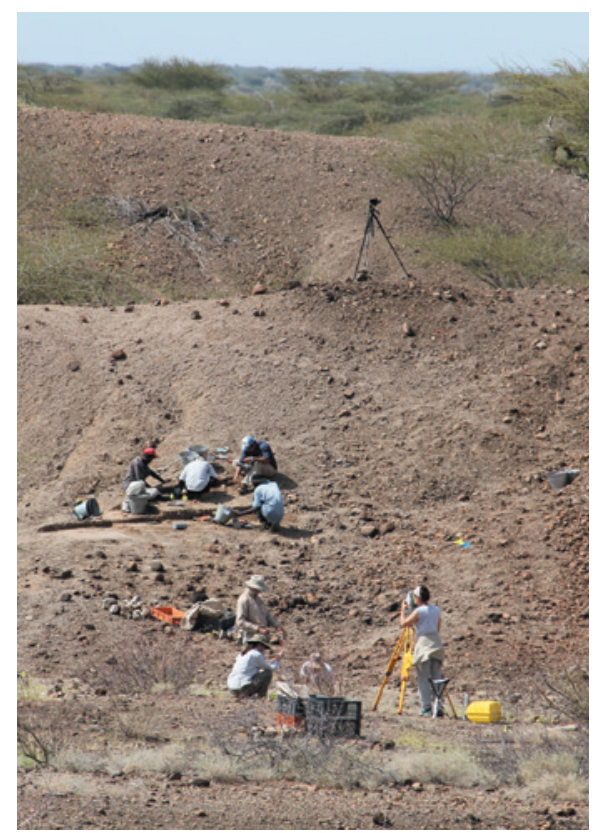

Excavators at Lomekwi, Kenya, in 2011.

New York set out in 2011 to find tools older than 3 million years, at a site west of Kenya's Lake Turkana. On a July day, the team took a wrong turn and happened upon a patch of land that seemed worth exploring. By tea time, they had found pieces of rock lying on the ground that looked like flakes left over from the manufacture of stone tools. Careful excavation of the patch revealed 19 buried artefacts, including stone core forms, and dozens more on the surface. One key surface find was a small rock flake, which fitted in a gap in a buried core as snugly as a jigsaw puzzle piece, confirming that the tools were made through a flaking process.

The tools come from sediments that Harmand's team dated to around 3.3 million years ago and are much larger than the Oldowan artefacts: some weigh as much as 15 kilograms. The team concluded that the tools represent a distinct culture, which they have named the Lomekwian culture after the site where the implements were found. "Lomekwi marks a new beginning to the known archaeological record," Harmand said at the meeting.

Hominin fossils and cut-marked animal bones have not been found at the site, so the team cannot yet say who made the tools or how they were used. But their discovery may deliver a fatal blow to the already fragile idea that complex toolmaking began with Homo. Harmand suggests that earlier species, such as Kenyanthropus platyops, bones of which have been found on the western shore of Lake Turkana, and A. afarensis, may have made tools by building on the cruder abilities seen in apes and monkeys. The Lomekwi tools were made in a forest environment, also questioning the idea that open landscapes catalysed tool use, said Harmand.

Alemseged sees the Lomekwi tools as vindication for his team's controversial find of cut-marked bones. Before Harmand's presentation, Alemseged's colleague Jessica Thompson, an archaeologist at Emory University in Atlanta, Georgia, presented an analysis of other animal bones from Dikika. None contained similar patterns to those reported in 2010, suggesting that the marks were made by something other than wear and tear - probably by tools.

The Lomekwi talk left David Braun, an archaeologist at George Washington University in Washington DC, itching for further details. He says that the tools look authentic, as does the date that Harmand and her team assert. The identity of their makers has aroused his curiosity: "What the hell do these things look like if they can use 15-kilogram tools?"

But he is most interested in what the Lomekwi tools meant for their creators. Did they offer an advantage over the other hominins that were around at the time, or was toolmaking more common 3 million to 4 million years ago than existing evidence suggests? "They're a gamechanger," he adds, "no matter what." -

\section{CORRECTIONS}

The News story 'Hope for science in fallout of nuclear deal' (Nature 520, 274-275; 2015) wrongly stated that Iran found a bank willing to accept its payment of dues to CERN. It was CERN, not Iran, that found the bank. In addition, the text implied that Iran is a full member of CERN - it is involved in specific projects at the lab. And the News story 'Leading scientists favour women in tenure-track hiring test' (Nature 520, 275-276; 2015) misidentified Virginia Valian as a linguist. She is a psychologist. It also misrepresented her views on the study by Williams \& Ceci: she has reservations about aspects of the study's methodology. 